\title{
Optimal Conditions for Acquiring Cathodoluminescence (CL) Images Using a Cold-Field Emission Scanning Electron Microscope.
}

Jacob L. Mey and Angela V. Klaus

American Museum of Natural History, New York, NY 10024, USA.

Natural zircons $\left(\mathrm{Zr}\left[\mathrm{SiO}_{4}\right]\right)$ usually cathodoluminesce (CL) brightly under a scanning electron beam, typically displaying a complex pattern of parallel bands epitaxial to the crystallographic facets of the crystal rim or the core shape. These bands are typically not visible in backscattered electron (BSE) images or secondary electron (SE) images. Therefore, these bands do not represent detectable atomic number differences in the crystal lattice or topographical features on the surface. The CL of zircons is most likely caused by slight fabric strains related to deformation of the crystal lattice[1]. Such slight differences in fabric can also be caused by trace amounts of elemental misfits in the crystal framework, various growth events, or failed annealing during metamorphism throughout the zircon's geological history [2]. Fabric characteristics related to element traces causing crystallographic misfits are not easily quantified with analytical techniques such as energy dispersive $\mathrm{x}$-ray spectroscopy (EDS) mapping or wavelength dispersive $\mathrm{x}$ ray spectroscopy (WDS) analysis $[1,2]$.

Zircons from a kimberlitic type rock from Telemark of central Norway [3] were analyzed using a Hitachi S-4700 cold field emission (FE) scanning electron microscope (SEM) equipped with BSE (GW Electronics - Centaurus), EDS (Princeton Gamma Tech) and high resolution CL (Gatan MonoCL 3) detectors. High resolution CL images of the zircons were collected with several different beam settings, including various beam voltages $(\mathrm{kV})$ (Figure 1), beam current $(\mu \mathrm{A})$ and acquisition scan speeds (dwell time). The resulting images represent resolution loss or gain for different levels of zircon CL intensity in the detectable spectrum ranging from 400-880 $\mathrm{nm}$. Spectra from the various beam conditions were also collected and compared in an effort to quantify optimal signalto-noise ratio versus resolution gain or loss.

The results of this study show that a powerful beam is not always the right approach when dealing with low intensity CL signals as a method for resolving fabric differences in silicates. The loss of resolution with increasing beam power is significant as the beam interaction volume increases. Also, as shown in an earlier study [4], the effects of beam damage caused by microprobe analyses showed a marked effect on the CL intensity in several zones in the zircon. Most notably in the central core of the zircon where CL is naturally absent, a clear CL signal was developed as a consequence of the beam-zircon interaction (Fig. 1). This effect with varying beam conditions is also showing different and increasing levels of intensity, clearly distinguished from the undamaged areas with progressive beam power.

[1] F. Bertram et al., App. Physics Lett., Vol. 74, No. 3. 18. (1999)

[2] S. Bodorkos et al., American Jounal of Science 300 (1), p. 60-82. (2000)

[3] J. L. Mey, Cand. Scient. Thesis, University of Aarhus, Denmark (1999)

[4] Mey, J. L. and Klaus, A.,. Micr. and Microanal. Vol. 11, CD 2, \# 267) (2005) 


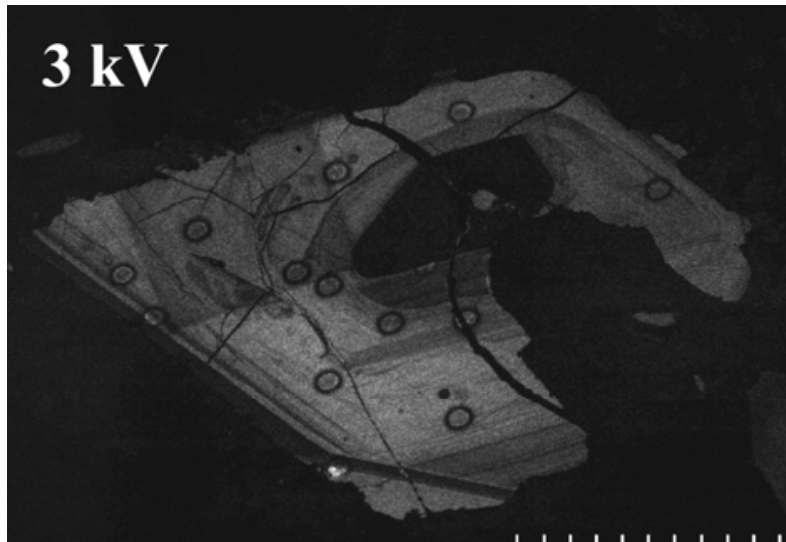

Analyt5uA 3.0kV 12.3mm ×800 OTHER1 9/19/05 15:41 '50.0um

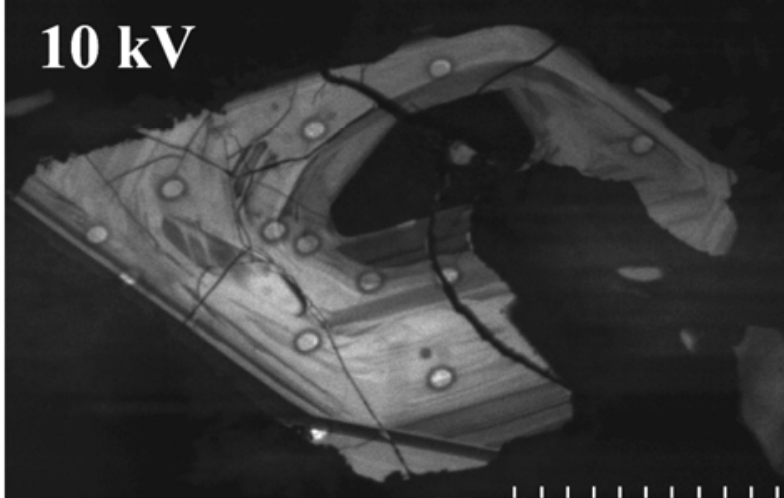

Analyt5uA $10.0 \mathrm{kV} 12.4 \mathrm{~mm} \times 800$ OTHER1 '9/19/0 05 '16:3350.0'um

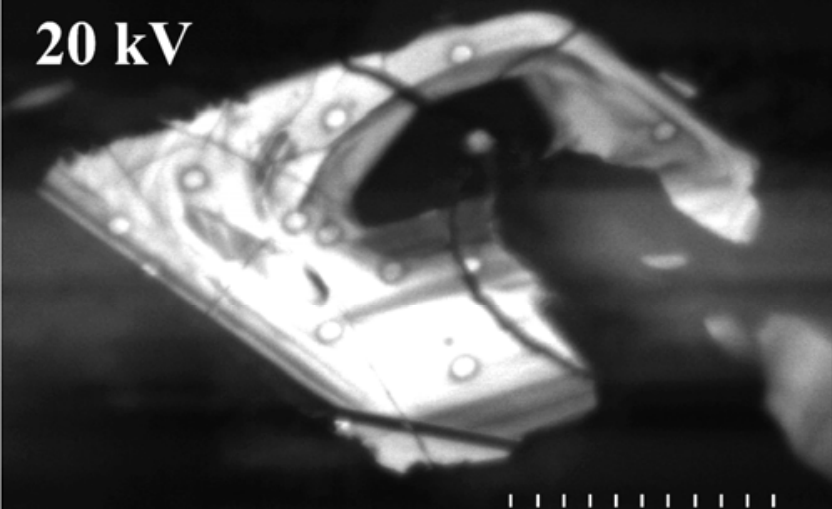

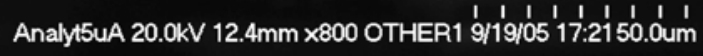

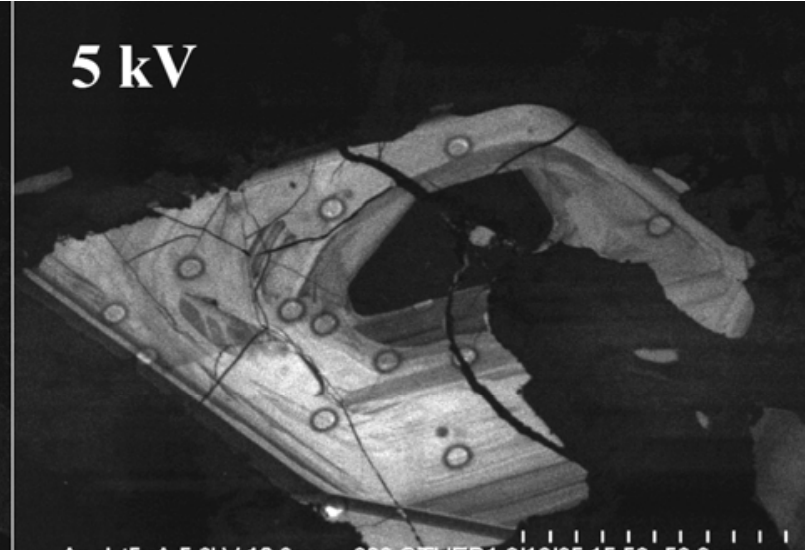

Analyt5uA 5.0kV $12.3 \mathrm{~mm} \times 800$ OTHER1 9/19/05 15:53 '50.0um

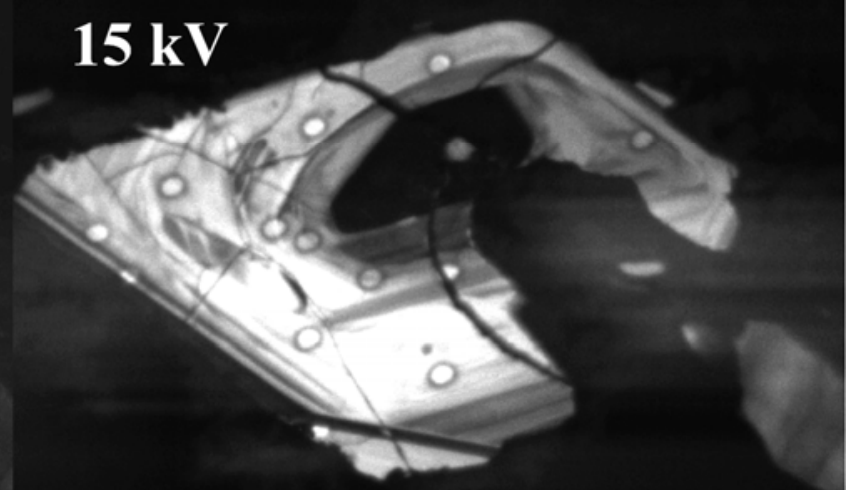

Analyt5uA $15.0 \mathrm{kV} 12.4 \mathrm{~mm} \times 793$ OTHER1 'و19/05 17:0250.0um

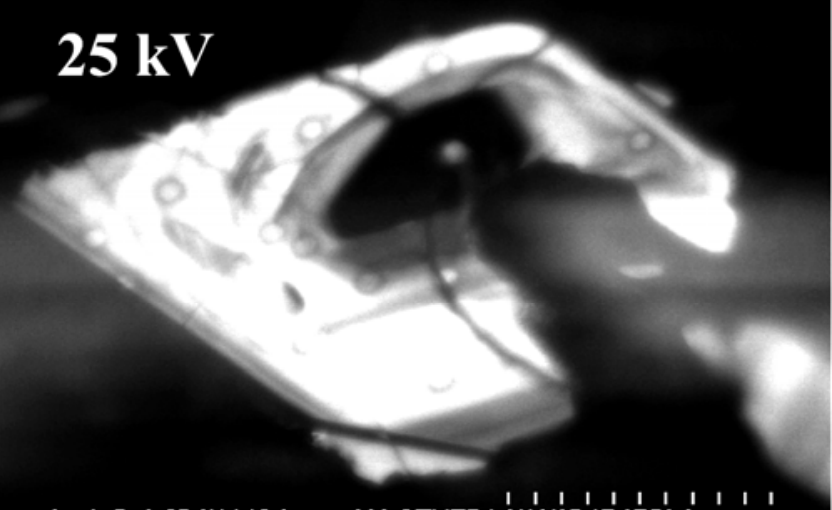

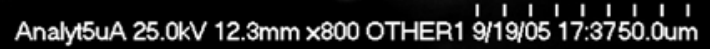

Results of changing $\mathrm{kV}$ on the CL signal 